\title{
Students' Perception to Online Distance Learning (ODL) and Socio-Emotional Skills During Covid-19 Pandemic
}

\author{
Alicia Jane F. Peras \\ De La Salle University \\ Maricar S. Prudente \\ De La Salle University
}

This study assessed the perception of online distance learning and the socio-emotional learning skills of grade 11 chemistry students in the Philippines during the Covid-19 pandemic. The Socio-emotional Skills Domains of Science Students Questionnaire (SSD-SSQ) is administered at the end of the school year. The study revealed high average socio-emotional skills in all the socioemotional learning domains (TaskPerformance, Emotion Regulation, Collaboration, Openness, Extraversion, and Compound Skills). Thematic Analysis is utilized in the research to determine the perceptions of the students. Responses of the students in their E-Portfolio were collected and analyzed. The study generated the following themes: opportunities to express, awareness and management of emotions, variation of activities, and interaction and support system. This study revealed the importance of socio-emotional learning in developing resiliency.

Keywords: socioemotional learning, online distance learning

\section{INTRODUCTION}

The effect of the Covid-19 pandemic brought a massive change in the current lifestyle. The immediate need to ensure public health and safety became the top priority. As a response to the current situation, many schools worldwide need to temporarily close in containing the spread of the virus and possible contaminants (UNESCO, 2020). Twenty-eight million Filipino learners from over 1.2 billion learners all around the globe are affected by the closure of schools (UNESCO, 2020). As of September 2021, the Philippines will be one of the few countries that have yet to offer a face-to-face setup.

In terms of the effect of the outbreak on mental health, students have higher vulnerability comparing to adults. According to Rodriguez-Hidalgo, Pantaleon, Dios, and Falla 2020, students faced stricter lockdown measures and fewer coping resources leading them to be more susceptible to stress and anxiety. The uncertainty and danger associated with the changed in the learning and assessment procedures, shift from face-to-face classroom to online/distance learning, and adapting to new methods heighten their anxiety (Rodriguez-Hidalgo, Pantaleon, Dios, and Falla 2020).

According to Price and Duman 2020, chronic stress, anxiety, and unregulated emotion disrupt the neuroplasticity in the brain, which is essential for learning. Chronic stress halts the ease of forming new neurons. (Price, R., and Duman, R., 2020). The regions in the brain like the hippocampus and medial 
prefrontal cortex (mPFC) play vital roles in learning but are related to emotions (Vogel, S.; Kluen, L.M.; Fernandez, G.; Schwabe, L., 2018). When a person is stressed, the encoding of memories will only happen in the hippocampus regardless of the new information associated with prior knowledge. Stress disrupts the activities of the mPFC. It could link to a possible reason why students may blank during an exam if they are experiencing a high level of stress regardless of their content mastery (Vogel, S. \& Schwabe, L. 2016).

The socioemotional learning of students during this outbreak plays a vital role in shaping their readiness to learn, ease in the acquisition of new information, and motivation. It is already challenging to teach chemistry because of the inherited demotivation on the perception of students. These demotivation and unregulated emotions are reinforced by the uncertainties of studying online during a pandemic.

The Collaborative for Academic, Social, and Emotional Learning (CASEL) model defines SocioEmotional Learning (SEL) as the process through which students and adults acquire and effectively apply the knowledge, attitudes, and skills necessary to understand and manage emotions, set and achieve positive goals, feel and show empathy for others, establish and maintain positive relationships, and make responsible decisions. The knowledge, skills, and attitudes (KSA) are key components that affect the quality of interaction of students with others, as well as their level of adaptability to the complexity of life. The school is one of the formation pillars in molding socio-emotional learning. The National School Climate Center (NSCC) 2007 used the word 'school climate' to describe the quality and character of life in school. The school climate is closely affected by the experiences of its students, parents, and even school personnel. The school climate also 'reflects norms, goals, values, interpersonal relationships, teaching and learning practices, and organizational structures' (NSCC, 2017).

Pachuki, Ozzer, Barrat, and Cattuto in 2015 suggested that the structure of network interaction of students heavily influenced their robustness.

According to Hefner and Eisenberg 2009, a learner with low perceived quality of support has a greater probability of experiencing difficulties in mental health. After all, learners mostly spend their time in school-- interacting with peers, classmates, and even their teachers. The different social, developmental, and academic challenges encountered in school help shape the minds of learners. According to Buckley and Lee 2018, the extent of involvement of students in their respective curricular and extracurricular activities are good indicators of their psychological well-being and distress. In the absence of a face-to-face set up, it highly affects the formation of the students and the development of necessary life skills.

\section{METHODOLOGY}

After one year of ODL, student's perception of learning and level of socio-emotional (SEL) skills are determined. This study utilized the revised framework of The Big Five Personality Model from OECD in determining the level of SEL skills. The Socioemotional Skill Domains of Science Students Questionnaire (SSD-SSQ) is administered. There are 60 questions divided into six categories or domains-Task Performance, Emotional Regulation, Collaboration, Openness to Experience, Extraversion, and Compound Skills. These six domains are from the Big Five Model.

The insights and perceptions of students are narrated and expressed in their Chemistry E-Portfolios. The insights were collated and organized to assess the perceptions and attitudes of the students towards Chemistry learning. Insights of students taken from their respective E-Portfolio, as well as the teacher and observer's feedback, were encoded, categorized, and analyzed using Braun and Clarke's 2006 thematic analysis.

\section{RESULTS AND DISCUSSION}

\section{Assessing the Perceptions and Attitudes of Students in Learning}

The perceptions and insights of students recorded in their E-Portfolios were encoded, categorized, and summarized using NVivo following protocols from Thematic Analysis by Braun and Clarke 2006. The following themes emerged: Opportunities to Express, Awareness and Management of Emotions, Variation of Activities, and Interaction and Support System. 


\section{Opportunities to Express}

One of the themes generated from the insights and reflections of students is their opportunities to express themselves. A couple of students conveyed that they appreciate given avenues where their voices can be heard and much more if their opinions materialized during classroom instructions. Shown below is an excerpt from the E-Portfolio of student B41, expressing how student feedback influenced conducting unit tests.

'... she [the subject teacher] checks for feedback regarding our class and uses this information to further improve it. This can be seen in my latest test as I noticed that I had more time in order to make sure that I was confident in my answers'

In addition, some students also expressed that they enjoyed sharing and discussing their ideas with their classmates through discussion boards. Regardless of the virtual structure, they can connect and communicate with their peers and classmates through the discussion boards interaction. Shown below is an excerpt from the E-Portfolio of student C2. Student C2 expressed his enjoyment with discussion board activities. He also recognized the responsibilities it holds once they shared and communicated their ideas to others.

'...one of the highlights during the first few sessions would be the discussion board sharing where broad questions would be given and we have the general freedom to address them in whatever way shape or form we desired. That further intrigued my interest as it not only taught you how to express yourself and your ideas, however, to make meaning of everyone else ideas. These small things we learn in school are all the more applicable in real life as you find parallels between that discussion board activity to social media comment sections.'

Apart from the discussion boards, the opportunity for them to express and share their ideas with their classmates, in general, felt that they formed a more intimate and personal relationship with their classmates and helped each other by giving constructive feedback. Shown below is an excerpt from student A65. Student A65 expressed how he appreciated being able to give and receive feedback from his classmates.

I think that what is really important is to be open to other people as well. I learned that it is best to share your ideas with others and be able to gain insights as well from them and receive feedback in order to improve one's knowledge when observing. Especially during this pandemic, learning chemistry in online classes can be a bit sad since we would usually go to the laboratory but taught me to be more creative in sharing my ideas and communicating with others as well.'

\section{Awareness and Management of Emotions}

The majority of the responses of students fall under the category of awareness and ability to manage emotions. A range spectrum of emotions is evident with their insights. While students are conveying their negative feelings like physical and mental exhaustion, anxiety, and demotivation, a huge percentage of the responses showed how they manage their perceptions. Many students directed their emotions and shifted to the positive spectrum of being hopeful and grateful. Shown below is an excerpt from student C42, expressing his difficulty with online learning. Student A38 also conveyed how he managed his perceptions.

'...One would assume that staring at a teacher giving a lecture for the same amount of time would require less effort. Yet, for some reason, I found myself blanking out several times in class. I found myself having difficulty actually understanding the lesson. I found myself falling asleep a couple of times, despite getting a good night's rest. It was harder to immerse 
myself in a proper "learning environment", thus it was harder for my brain to be motivated to actually, well, work.

'A new year, a new system means new challenges for me to face. These challenges presented themselves to me early on the semester through constant headaches, eye strain, lousy WiFi, regular computer shutdowns, and more. I could go on and on about the different problems I have faced throughout the school year, but this paper is meant to show that no matter how bad a situation is, people can grow to become better people in every way.'

Another contributor to the spectrum of emotions is the unwanted pressures created from their other commitments. These commitments add up to the feeling of being overwhelmed. Apart from regular classes, students may join different interest clubs, committees, and varsity teams. While the primary goal of the extra-curricular activities is for students to have an avenue to relax and practice their other interests, some express that it sometimes adds up to their fatigue. An excerpt from students A26 and C19, respectively, is seen below revealing how their other commitments add to their mental and physical exhaustion.

'I tend to lose my motivation due to all the upcoming homework, tests, and submissions that are due before the sem break starts. I also have XDL [Dragon and Lion Dance] training every Thursday which involves workout ... as a result, I am constantly feeling muscle fatigue and desiring to rest instead of dedicating my time and effort to do my needed tasks such as my deadlines.'

After a hard day's work and a Council of Class Officers (CoCO) meeting, I found myself absolutely exhausted, drained, and tired from all the tasks and responsibilities that were thrown my way. Even with this, I somehow managed to take out my Chemistry book, and attempt to advance my study for the next session.

Moreover, transitioning to senior high school, college preparation, and expectations also add to the mental pressure of students. These additional stressors, however, are perceived differently. Some students view mental stressors as positive attributes to be better, while others perceive them oppositely. Excerpts from students C43, A48, B13, and C49, respectively, can be seen below.

'I was scared coming to Grade 11 because I heard from others that the workload is heavy and I was expecting the lessons to be super difficult.'

'My brother saw that I was not serious at all with my academics and because of this, he pulled me to the side and talked to me about how I should take the school work seriously. He tells me that I should make sure to perform at my best so that I can get into a good college when I grow older. These school works are important for my life so that I can get a good job in the future.'

I have no qualms with what we are learning, and I am sure that what I learn in chemistry in senior high will be useful in the event that I pursue a science-related course in the future. I am always eager to learn something that will benefit my life, even if it may come off as a pretty niche topic, if it will help provide future opportunities, I will look into it. That is pretty much my motivation for my senior high years, after all in one year we will be undertaking college applications and exams, which is why I want to do the best I could this year and next year.'

150 Journal of Higher Education Theory and Practice Vol. 21(15) 2021 
'...not saying I don't like science as a subject, I would wanna get in it because my dad is a chemist and I mainly look up to him, but it just doesn't work the same with me.'

The majority of the negative emotions felt by the students attributed to their mental and emotional struggles more than logistics concerns. There are fewer students expressing that their poor participation in class is because of connectivity issues. The majority pointed out that mental stress is what they struggled with the most. Shown below is an excerpt from the E-Portfolio of student A38, expressing how internet connection and inefficient gadget disrupts his academic performance. Student A64, on the other hand, pointed out that his disposition led him to poor academic performance.

'I am in no way an exemplary student based on my grades as I would more often than not either disconnecting from my class, late to my submissions, or even something as simple as explaining. Me not being able to attend classes has heavily affected my performance in assessments as I would sometimes not understand a single statement of the lesson. Once I know it, I lack the critical factors in my head to explain my work correctly without being scared of my laptop crashing or even my WiFi dying.'

'...I would literally have so much time but then I wouldn't actually study because of certain problems that I have with me, one reason would be that I am actually really tired both physically and mentally, I feel as if I'm so tired after every school day and it just keeps on repeating over and over again.'

Many students genuinely express their topmost feeling this school year and generously disclose how these feelings affected their perceptions and attitudes to learning. Some students managed to look beyond their personal feelings, acknowledging and empathizing with other people. After one year of online learning, several students were able to adjust and managed their perceptions.

Another proof of this is students developing empathy for fellow students and even their teachers. They were able to go beyond their personal experiences. Student A23 acknowledge his disposition and empathize with others who are in his opposite state. Student $\mathrm{C} 7$ acknowledges the quick adjustment of teachers in an online learning.

'My transition from physical to online distance learning was sort of difficult for me. Many adults think that 'oh the kids will get used to it since they're on their computer all day' or 'it's okay, that's not too different from watching anime all day'. But it's actually quite hard for most students to adjust to this, especially those with poor living conditions. I am lucky enough to be part of a privileged family and have access to many devices that I can use for online distance learning, but I've heard around some families have to share one laptop or device which makes it difficult for the kids.'

I find chemistry class very interesting as I experience this new way of learning. I find it admirable how the teachers are able to quickly adapt to this new set-up given the situation.

\section{Variation of Activities}

Other themes that emerged from the E-Portfolios are their appreciation and suggestions for varied activities to keep the chemistry learning engaging and motivating. These variations of activities were a response to the diversity and individuality of the students. The colorful and diverse personalities of the students were evident in the construction of their E-Portfolios that show their genuineness and uniqueness. Students demonstrated their creativity in expressing their insights like poems, narratives, memes, or even chemistry jokes. 
It is an impressive indicator to showcase the individuality of the students. But striking a balance of addressing each of their need, especially in an online class is challenging. An excerpt from students B13 and $\mathrm{C} 42$ shows that the 2 have different learning preferences.

'I often take pride in the fact that I am a heavy note-taker, ever since junior high school I would copy the presentation word per word into my notebook, and along with it any other useful information that the teacher might say ... due to the nature of the situation, during synchronous, I try to take down what is on the slides only for the discussion to proceed while I'm still behind. My last qualm with ODL is the fact that I just can't get the same feeling of learning through reading the notes provided by the teacher compared to taking down notes in a synchronous session.'

'...I find Chemistry quite difficult. This is because, at a certain point, there are things in Chemistry that simply cannot be visualized. As a visual learner, this is very detrimental to me and was another big reason for my struggles.

Existing classroom activities recognized by students cultivate engaging classroom interaction. Although, several students said that physical experiments are significant in learning chemistry.

'...online chemistry is fun and memorable, but considering unideal situations such as factors of lost WiFi connections and unstable bandwidth we as a class have helped one another to cope with these problems and making learning fun. One great example of this is the Everyday Chemistry segment, this happens during the start of the class, and with this simple activity wherein a person shares how chemistry is seen in our daily lives. This has been greatly helpful for creating bonds and having fun at the same time learning new things such as the chemistry behind batteries, coffees, and even farts. These small chemical reactions are what makes life possible and this has been a realization for me, it has opened my eyes to see the world in a different way and learn how chemistry is literally around us helping us make our lives easier. This whole experience sums up memories and learning.

'Describing chemistry as a class, wasn't as difficult and the teacher was able to make chemistry a very interesting subject. One of the required tasks the teacher has assigned us to do was by class number to present something related to chemistry. At first, I thought that this activity that Ms. Peras assigned us to do was pointless and has no relevance to my knowledge for chemistry class. However, after presenting and preparing for my presentation I found it significant since the topic I choose was able to help me with its connection to our succeeding topics'

'Personally, I found the Performance Task to be a highlight of my experience in studying Unit 1, I was able to practice these (Science Process) skills in a comprehensive and professional manner.

'...For Chemistry, the lack of activities that we have been accustomed to in the laboratory is something new for all of us. Many of these experiments have turned virtual, with the use of videos and websites that although have their deficiencies, are the best that could be done during virtual learning...some of the struggles I have encountered in this unit include the set-up for this school year. It being online classes for the entire school year, it is saddening that there would not be any physical lab experiments or trials that we were accustomed to doing in Junior High School. As a student, it is cool to see how the application of what you learned in the classroom is done in real life, which therefore enhances your curiosity with the subject.'

152 Journal of Higher Education Theory and Practice Vol. 21(15) 2021 
The statements above are from students C20, A12, C19, and C63. Student C20 and A12 expressed how the activity, Everyday Chemistry, motivated them to interact with the class by sharing one daily application of chemistry and how it enables them to have a glimpse of the personality of their classmates despite limited interaction with them. Student C19 expressed that working with his Performance Task was his highlight in one of their units in chemistry since he was able to apply what he learned. Lastly, student C63 expressed that physical experiments helped him enhance his curiosity towards the subject.

\section{Interaction and Support System}

The last theme observed from the E-Portfolio is the importance of interaction and support systems in creating a positive and hopeful disposition. Virtual presence as means of support system played a significant role, not as powerful as the physical presence, but enough to help them cope and adjust. Support from their friends, classmates, and even teachers was acknowledged and affirmed by the students as one of the integral factors in developing a more hopeful disposition. The statements below were from student C18. Student C18 conveyed his perception about studying online and the importance of interaction and support systems to him.

'Throughout the online distance learning, we students have been presented with multiple hurdles and challenges that we had to go through. Aside from problems with WiFi, it has also been quite difficult to understand complex lessons that require deep knowledge of the topics at hand. None of us students would be able to pass this online class set-up if not for the help of the teachers who struggled and put up with the students who need their help the most'

'Throughout this semester, I think one thing that really inspired and helped me get through this would be my friends and classmates who kept pushing to be better even if they were struggling. One thing that really sets me back in studies would be my lack of effort, and seeing my classmates push through really inspired me to get better myself.'

Apart from their attitudes and perceptions of learning, the level of socio-emotional learning of students is assessed.

TABLE 1

SUMMARY OF THE DIFFERENT SOCIO-EMOTIONAL LEARNING DOMAINS

\begin{tabular}{ccccc}
\hline Socio-Emotional Skills Domain & $\begin{array}{c}\text { Number of } \\
\text { Items }\end{array}$ & Mean & SD & Interpretations \\
\hline $\begin{array}{c}\text { Task Performance/ } \\
\text { Conscientiousness }\end{array}$ & 6 & 2.90 & 0.39 & High Average \\
\hline Emotion Regulation/ Emotion Stability & 10 & 2.97 & 0.32 & High Average \\
\hline Collaboration/ Agreeableness & 9 & 3.03 & 0.28 & High Average \\
\hline $\begin{array}{c}\text { Open-mindedness/ } \\
\text { Openness to Experience }\end{array}$ & 14 & 3.15 & 0.16 & High Average \\
\hline Engagement with Others/ Extraversion & 5 & 3.11 & 0.13 & High Average \\
\hline $\begin{array}{c}\text { Compound Skills: Self-efficacy, } \\
\text { Critical Thinking/ Independence, Self- } \\
\text { Reflection/ Metacognition }\end{array}$ & 16 & 3.03 & 0.31 & High Average \\
\hline
\end{tabular}


Students' level of socioemotional skills was determined using SSD-SSQ. The values below are used to interpret the survey (Arevalo and Prudente, 2020).

3.26- 4.00 - Excellent Socioemotional Skills Domain

2.51 - 3.25 - High Average Socioemotional Skills Domain

1.76- 2.50 - Low Average Socioemotional Skills Domain

1.00- 1.75 - Poor Socioemotional Skills Domain

All the six domains of socio-emotional skills reported a high average interpretation. Thematic Analysis supplements the general disposition of the students. While several students expressed negative emotions, the majority managed their perception and shifted to a more positive side of the spectrum.

\section{CONCLUSIONS}

The current pandemic was the culprit to the abrupt shift in the learning modality. Many schools in the Philippines shifted from face-to-face instruction to online distance learning. There is an inherent difficulty in teaching chemistry, but the sudden shift to ODL made it challenging.

There are four primary major themes generated from the students' E-Portfolio regarding their perceptions of learning. The four themes are as follows: opportunities to express, awareness and management of emotions, variation of activities, and interaction and support system. Students have mixed perceptions and attitudes towards learning, but the majority expressed how to manage emotions to a more hopeful and grateful disposition.

Lastly, this study also showed that students have a high average level of socioemotional skills. The students answered the questionnaire towards the end of the online distance learning. Despite the challenges, this study showed that students were able to adapt to the changes. Students still acknowledge that the present condition will never be ideal and pose difficulties.

\section{REFERENCES}

American Chemical Society. (2020, October). Introduction to the Journal of Chemical Education Special Issue on Insights Gained While Teaching Chemistry in the Time of COVID 19. Journal of Chemical Education, pp. 2375-2377.

Arevalo, I.J., Prudente, M., \& Caliste, R. (2020). Socioemotional Skill Domains in Robotics Performance Tasks using Design Thinking Process. IC4E 2020: 2020 the 11th International Conference on EEducation, E-Business, E-Management, and E-Learning, pp. 81-86.

Assessment Work Group. (2019). Student social and emotional competence assessment: The current state of the field and a vision for its future. Chicago, Il: Collaborative for Academic, Social, and Emotional Learning.

Cahapay, M. (2020). Rethinking Education in the New Normal Post-COVID-19 Era: A Curriculum Studies Perspective. Aquademia, pp. 1-5.

Campbell, M.C.-I. (2012). Emotional Presence, Learning, and Online Learning Environment. The International Review of Research in Open and Distance Learning, 13(4), 270-292.

Currie, H.N. (2020, October). Mindful Well-Being and Learning. Journal of Chemical Education, pp. 2393-2396.

Development, O. f. (2019). Social and Emotional Skills: Wellbeing, connectedness, and success.

Dresser, J.S. (2019). Social-Emotional Learning (SEL) in a Field Course: Preservice Teachers Practice SEL-Supportive Instructional Strategies. Journal of Inquiry \& Action in Education, pp. 36-67.

Espinosa, A., Monterola, S.L., \& Punzalan, A. (2013). Career-Oriented Performance Tasks in Chemistry: Effects on Student's Critical Thinking Skills. Education Research International, pp. 1-10.

Hamedani, M.Z-H. (2015). Socio emotional learning in high school: How three urban high school engage, educate, and empower youth--Cross-case analysis. Stanford, CA: Stanford Center for Opportunity Policy in Education. 
Oliver, B. (2018). Socio Emotional Learning Toolkit:Built Upon a Neurodevelopmental Culturally Responsive Framework. Indiana: Indiana Department of Education.

Organization for Economic Cooperation and Development. (2020). Supporting the continuation of teaching and learning during the COVID-19 Pandemic. Organization for Economic Cooperation and Development.

Osher, D., \& Beg, J. (2017). School Climate and Socio-Emotional Learning: The Integration of the Two Approach. Edna Bennet Pierce Prevention Research Center: Pennsylvania State University.

Schonert-Reichl, K. (2017). Socio and Emotional Learning and Teachers. The Future of Children, 27(1), 137-166.

Tria, J. (2020). The Covid-19 Pandemic through the Lens of Education in the Philippines: The New Normal. International Journal of Pedagogical Development and Lifelong Learning, 1. 